\title{
The Bacterial Biogenesis of Isobutyraldoxime $O$-Methyl Ether, a Novel Volatile Secondary Metabolite
}

\author{
By DAVID B. HARPER* AND JOHN NELSON \\ Faculty of Agriculture and Food Science, Queen's University of Belfast, Newforge Lane, Belfast \\ BT9 5PX, Northern Ireland, U.K., and Department of Agriculture, Northern Ireland, U.K.
}

(Received 17 November 1981 ; revised 18 January 1982)

\begin{abstract}
Production of the volatile metabolite, isobutyraldoxime $O$-methyl ether (IBME) by a Moraxellalike organism NCIB 11650 was investigated under a variety of environmental conditions using gas chromatography. Under aerobic conditions up to $10 \mu \mathrm{g}$ IBME $\mathrm{ml}^{-1}$ was produced on mineral salts media containing $0.5 \%(\mathrm{w} / \mathrm{v})$ glucose or succinate as sole $\mathrm{C}$ source with $0 \cdot 1 \%(\mathrm{w} / \mathrm{v})$ $\mathrm{NH}_{4} \mathrm{Cl}$ as sole $\mathrm{N}$ source. Exogenous L-valine further stimulated IBME formation up to $25 \mu \mathrm{g}$ $\mathrm{ml}^{-1}$ but supplementation of the medium with D-isomer or other amino acids had little effect on IBME production and did not lead to the appearance of analogues of IBME. Trapping experiments using $\left[{ }^{14} \mathrm{C}\right]$ valine confirmed that IBME was derived from this amino acid. Several other bacterial species examined, e.g. Alcaligenes sp. NCIB 11652, another Moraxella-like organism NCIB 11651 and Pseudomonas sp. NCIB 11653 also produced IBME under similar conditions. The Alcaligenes strain synthesized up to $20 \mu \mathrm{g} \mathrm{ml}^{-1}$ in the absence of valine and up to $90 \mu \mathrm{g} \mathrm{ml}^{-1}$ in its presence.

The production of IBME exhibited many features characteristic of the formation of a secondary metabolite. Thus biosynthesis was confined to a narrower range of temperature than cell division, was almost completely suppressed by $300 \mathrm{~mm}$-phosphate and was inhibited by high concentrations of readily utilizable C sources. Although IBME synthesis in the Moraxella-like organism NCIB 11650 appeared to be growth-related, its formation by both the Alcaligenes sp. and the Moraxella-like organism NCIB 11651 was delayed until the late-exponential and earlystationary phases of growth. The biological significance of this novel class of secondary metabolite is discussed and a possible biosynthetic route proposed.
\end{abstract}

\section{INTRODUCTION}

Investigations using combined gas chromatography/mass spectrometry (GC/MS) of volatile headspace components generated during spoilage of meat (Gibbs et al., 1979) revealed that pure cultures on sterile beef of three psychrotrophic micro-organisms (a Moraxella-like organism NCIB 11650 originally described as an Aeromonas sp., Alcaligenes sp. NCIB 11652 and the Moraxella-like organism NCIB 11651) out of twenty isolated from spoiling meat, produced substantial quantities of an unidentified compound of molecular weight 101 . This compound gave a mass spectrum similar to that described earlier (Freeman et al., 1976) for an unknown volatile compound formed on sterile chicken meat by two pseudomonads [Pseudomonas putida and Pseudomonas sp. NCIB 11653, originally reported by Freeman et al. (1976) as a Moraxella sp.]. Subsequent studies (Harper \& Gibbs, 1979; Harper, 1980) identified the compound as isobutyraldoxime $O$-methyl ether, $\left(\mathrm{CH}_{3}\right)_{2} \mathrm{CH}-\mathrm{CH}=\mathrm{NOCH}_{3}$, (referred to hereafter in this paper as IBME) and demonstrated that it was produced in association with the related catabolites, isobutyronitrile and methacrylonitrile, when both the Moraxella-like organisms (NCIB 11650 and NCIB 11651) were grown on slants of nutrient agar. A compound tentatively identified on the basis of its mass spectral characteristics as methacrylaldoxime $O$-methyl ether was also produced. 
Harper \& Gibbs (1979) suggested that a parallel could be drawn between the formation of IBME by bacteria and the biosynthesis of the cyanogenic glucoside, linamarin, by flax seedlings (Tapper et al., 1967; Hahlbrock et al., 1968; Tapper \& Butler, 1971, 1972). The investigations of the latter workers indicated that both isobutyraldoxime and isobutyronitrile were intermediates in the biosynthesis of linamarin from valine. The effect of supplementation of nutrient agar with valine on the formation of IBME and nitriles by cultures of the Moraxella-like organism NCIB 11651 was therefore examined by Harper \& Gibbs (1979). Cultures on such enriched media showed greatly enhanced accumulation of these catabolites, implying that valine was indeed the probable precursor.

In an attempt to assess the significance of IBME in bacterial metabolism the present paper describes quantitative investigations of the production of IBME by bacteria grown in shake flasks on synthetic media of different compositions under various growth conditions. Also described are trapping experiments using $\left[{ }^{14} \mathrm{C}\right]$ valine designed to confirm the status of valine as a precursor of IBME. The tentative identification of methacrylaldoxime $O$-methyl ether by Harper \& Gibbs (1979) as one of the products of growth of the Moraxella-like organisms (NCIB 11650 and NCIB 11651) on nutrient agar is confirmed by synthesis of the compound.

Although most of the study has been confined to a single IBME-producing species, i.e. the Moraxella-like organism NCIB 11650, comparisons have been made in certain experiments between IBME production by this organism and both the Alcaligenes sp. and the Moraxella-like organism NCIB 11651 isolated by Gibbs et al. (1979), and the Pseudomonas sp. NCIB 11653 examined by Freeman et al. (1976).

\section{METHODS}

Organisms and culture conditions. The Alcaligenes sp. NCIB 11652 and the Moraxella-like organism NCIB 11651 employed in the present study were first isolated from spoiling meat and identified by Patterson \& Gibbs (1977). Another Moraxella-like organism NCIB 11650 examined was also isolated from the same source by these workers and identified at the time as an Aeromonas sp., though subsequently reclassified by the National Collection of Industrial Bacteria (NCIB), Torry Research Station, Aberdeen, U.K. The Pseudomonas sp. NCIB 11653 investigated was that isolated by Freeman et al. (1976) from spoiling chicken meat and though originally reported as a Moraxella sp. was again reclassified by NCIB.

All organisms were grown on a defined medium of the following composition (g $\left.\mathbf{1}^{-1}\right): \mathrm{KH}_{2} \mathrm{PO}_{4}(4 \cdot 5)$; $\mathrm{K}_{2} \mathrm{HPO}_{4} \cdot 3 \mathrm{H}_{2} \mathrm{O}(10 \cdot 5) ; \mathrm{MgSO}_{4} \cdot 7 \mathrm{H}_{2} \mathrm{O}(0 \cdot 15) ; \mathrm{NH}_{4} \mathrm{Cl}(1 \cdot 0)$; succinic acid (5.0) or glucose (5.0). The pH of the solution was adjusted to 7.0 and the medium supplemented with a trace element solution $\left(10 \mathrm{ml} \mathrm{l}^{-1}\right)$ containing (g $\left.1^{-1}\right): \mathrm{ZnSO}_{4} .7 \mathrm{H}_{2} \mathrm{O}(0.04) ; \mathrm{Na}_{2} \mathrm{MoO}_{4} .2 \mathrm{H}_{2} \mathrm{O}(0.02) ; \mathrm{FeCl}_{3}(0.04) ; \mathrm{KI}(0.01) ; \mathrm{CUSO}_{4} .5 \mathrm{H}_{2} \mathrm{O}(0.004) ; \mathrm{H}_{3} \mathrm{BO}_{4}(0.05)$ and $\mathrm{MnSO}_{4} \cdot 4 \mathrm{H}_{2} \mathrm{O}(0.04)$. Where stated, the concentrations of both the carbon and nitrogen sources in the medium were altered and, in some experiments, valine and other amino acids were added at the concentrations given. The concentrations of phosphate and iron in the medium were also adjusted in certain experiments. Conical flasks ( $250 \mathrm{ml}$ ) plugged with cotton wool and containing $100 \mathrm{ml}$ culture medium were normally incubated at $15^{\circ} \mathrm{C}$ on an orbital shaker with an eccentricity of $2.5 \mathrm{~cm}$ at $120 \mathrm{rev} . \mathrm{min}^{-1}$. In some experiments cultures were incubated at a range of temperatures between $6.5^{\circ} \mathrm{C}$ and $21.5^{\circ} \mathrm{C}$. Inocula for experimental flasks consisted of $2 \mathrm{ml}$ of a culture of the organism grown for $48 \mathrm{~h}$ on normal liquid medium with succinic acid as sole carbon source. The growth of the organism was monitored by measuring the $A_{690}$.

Chemicals. Isobutyraldoxime $O$-methyl ether (IBME) was prepared directly by the action of methoxyamine hydrochloride on isobutyraldehyde rather than by methylation of isobutyraldoxime as previously described (Harper \& Gibbs, 1979), since the latter method gave rather poor yields due to substantial dehydration of the oxime to the nitrile.

Methoxyamine hydrochloride (Eastman-Kodak, $13.0 \mathrm{~g}$ ) and sodium bicarbonate $(16.8 \mathrm{~g})$ were dissolved in water $(200 \mathrm{ml})$ and redistilled isobutyraldehyde $(10.8 \mathrm{~g})$ was added with stirring at room temperature. The reaction mixture was allowed to stand at room temperature with stirring overnight. The upper layer of $O$-methyl oxime was then separated off, dried over anhydrous magnesium sulphate and fractionally distilled twice to give $8.1 \mathrm{~g}$ isobutyraldoxime $O$-methyl ether [b.p. $91-93^{\circ} \mathrm{C}$ at $99 \mathrm{kPa}(750 \mathrm{mmHg})$ ].

Methacrylaldoxime $O$-methyl ether [b.p. $105-107^{\circ} \mathrm{C}$ at $98.7 \mathrm{kPa}(748 \mathrm{mmHg})$ ] and isovaleraldoxime $O$-methyl ether [b.p. $94^{\circ} \mathrm{C}$ at $51.5 \mathrm{kPa}(390 \mathrm{mmHg})$ ] were prepared by a similar route from methacrolein and isovaleraldehyde, respectively.

$\mathrm{L}-\left[\mathrm{U}^{-14} \mathrm{C}\right]$ Valine $\left(10 \mathrm{mCi} \mathrm{mmol}^{-1} ; 370 \mathrm{MBq} \mathrm{mmol}^{-1}\right)$ and $\mathrm{L}-\left[1{ }^{-14} \mathrm{C}\right]$ valine $\left(57 \mathrm{mCi} \mathrm{mmol}^{-1} ; 2 \cdot 11 \mathrm{GBq} \mathrm{mmol}^{-1}\right)$ were obtained from Amersham. L- $O$-Methyl threonine was acquired from Sigma. 
Assay of IBME in culture media. Difficulty in finding both an adequate trapping technique for IBME and a suitable colorimetric assay for the compound led to the development of a gas chromatographic method for the quantitative determination of IBME in aqueous solution. The technique involved measuring by GC the concentration of IBME in a sample of headspace extracted from a sealed vial in which a standard volume of the solution to be assayed was equilibrated with headspace at $40^{\circ} \mathrm{C}$.

A sample of culture medium to be assayed ( $2 \mathrm{ml}$ ) was pipetted into a $25 \mathrm{ml} \mathrm{screw-capped} \mathrm{septum} \mathrm{vial} \mathrm{sealed} \mathrm{with}$ a Teflon-lined silicone disc (Tuf-bond: Pierce and Warrimer, U.K.). The sealed vial was placed in a boiling water bath for $5 \mathrm{~min}$ to kill bacterial cells and prevent any further metabolism occurring. After this treatment the vial was usually stored at $-15^{\circ} \mathrm{C}$ until it was convenient to perform the gas chromatographic assay. For analysis the vial was equilibrated at $40^{\circ} \mathrm{C}$ for $30 \mathrm{~min}$ in a water-bath and a sample of headspace (usually $2 \mathrm{ml}$ ) was extracted with a syringe and injected into a Pye-Unicam 104 (model 74) chromatograph equipped with a glass column $(1.5 \mathrm{~m}$ $\times 2 \mathrm{~mm}$ internal diam.) packed with Tenax GC (60-80 mesh) and operated at a nitrogen gas flow rate of $20 \mathrm{ml}$ $\min ^{-1}$. The temperature of the chromatograph oven was programmed at a rate of $24^{\circ} \mathrm{C} \min ^{-1}$ from $100^{\circ} \mathrm{C}$ to $200^{\circ} \mathrm{C}$. Eluting compounds were detected using a flame ionization detector. Under the conditions described, IBME eluted at a retention time of $3.8 \mathrm{~min}$ whilst methacrylaldoxime $O$-methyl ether and isovaleraldoxime $O$ methyl ether had retention times of 4.0 and $4.8 \mathrm{~min}$, respectively.

Investigations with standard solutions of IBME (up to $1 \mathrm{mg} \mathrm{ml}^{-1}$ ) indicated a linear relationship between the concentration of IBME in the solution in the vial and the peak height obtained on gas chromatography of the headspace in the vial. The lower limit of detection was $0.2 \mu \mathrm{g} \mathrm{ml}^{-1}$. This relatively simple method not only allowed the analysis of liquid media containing thick suspensions of bacteria, but also permitted the simultaneous detection of other related volatile compounds if present.

Determination of rate of loss of IBME from solution at various temperatures. A series of identical conical flasks $(250 \mathrm{ml})$, each containing $100 \mathrm{ml}$ of an aqueous solution of IBME (approximately $45 \mu \mathrm{g} \mathrm{ml}^{-1}$ ) and plugged with cotton wool, was placed on an orbital shaker with an eccentricity of $2.5 \mathrm{~cm}$ at $120 \mathrm{rev}$. $\mathrm{min}^{-1}$ and incubated at $15^{\circ} \mathrm{C}$. Samples $(2 \mathrm{ml})$ were withdrawn from the flasks at regular intervals and subjected to the standard IBME assay. Sampling was continued until the concentration of IBME in solution was less than $0.5 \mu \mathrm{g} \mathrm{ml}^{-1}$, but ensuring that no individual flask was sampled more than five times. The experiment was repeated at temperatures of $6 \cdot 5$, $10 \cdot 5,17 \cdot 5$ and $21^{\circ} \mathrm{C}$.

Calculation of total IBME generated during bacterial growth. The rate of loss of IBME from aqueous solutions under the conditions normally used in the culture of the bacteria was found to obey first-order reaction kinetics. This observation enabled the half-life of IBME in solutions at a number of temperatures to be calculated from the empirical data on the rate of loss collected at each of these temperatures. The half-life of IBME in solution at temperatures of $6 \cdot 5,10 \cdot 5,15 \cdot 0,17 \cdot 5$ and $21 \cdot 5^{\circ} \mathrm{C}$ was determined as $22 \cdot 0,16 \cdot 1,11 \cdot 5,10.6$ and $8 \cdot 1 \mathrm{~h}$, respectively.

Calculation of the total IBME generated by a bacterial culture at any particular point of the growth curve, from experimental observations of the concentration of IBME in the culture medium during growth and the half-life of IBME in solution, required the use of a general curve fitting process and modelling programme (RGG8) written in Fortran by Dr D. Stewart of the Biometrics Division, Department of Agriculture, N. Ireland. By an iterative process on an ICL 1906S computer the programme derived both the cumulative total of IBME lost from solution and that generated at any particular point on the growth curve.

Incorporation of $\left[{ }^{14} \mathrm{C}\right]$ valine into IBME. To normal culture medium $(40 \mathrm{ml})$ containing $0 \cdot 5 \%(\mathrm{w} / \mathrm{v})$ succinic acid and $0 \cdot 2 \%(\mathrm{w} / \mathrm{v})$ valine in a conical flask $(100 \mathrm{ml})$ was added $\mathrm{L}-\left[\mathrm{U}-{ }^{14} \mathrm{C}\right]$ valine $\left(10 \mathrm{mCi} \mathrm{mmol}^{-1}\right)$ or $\mathrm{L}-\left[1-{ }^{14} \mathrm{C}\right]$ valine $\left(57 \mathrm{mCi} \mathrm{mmol}^{-1}\right)$ to give a final specific activity of 5 to $7.5 \mu \mathrm{Ci} \mathrm{mmol}^{-1}$. After inoculation with the Moraxella-like organism NCIB 11650 the cultures were incubated under normal conditions at $15^{\circ} \mathrm{C}$ for $72 \mathrm{~h}$. Samples $(2 \mathrm{ml})$ of the culture medium were then pipetted into a number of $25 \mathrm{ml} \mathrm{screw}$-capped septum vials sealed with Teflon-lined silicone discs similar to those used in the standard IBME assay, except that each vial contained a $\mathrm{CO}_{2}$ absorption well comprising a small tube containing $30 \%(\mathrm{w} / \mathrm{v}) \mathrm{NaOH}(0 \cdot 1 \mathrm{ml})$ and a filter paper wick. The sealed vials were placed in a boiling water bath for $5 \mathrm{~min}$ to kill the bacteria. After equilibration at $40^{\circ} \mathrm{C}$ for $1 \mathrm{~h}$, headspace was extracted from a number of vials (in total 10 or $20 \mathrm{ml}$ ) and injected into a preparative gas chromatograph as described below. In addition, samples $(2 \mathrm{ml})$ of headspace were analysed at the same time for IBME using the standard assay procedure.

For separation and trapping of labelled IBME a Pye-Unicam (series 105) preparative gas chromatograph equipped with a glass column ( $2 \mathrm{~m} \times 8 \mathrm{~mm}$ internal diam.) packed with Tenax GC (60-80 mesh) was employed. The chromatograph was fitted with an effluent splitter so that, whilst a minor portion of the eluted compounds passed to a flame ionization detector, the major portion passed to a collection system consisting of a highefficiency, high volume trap immersed in a cooling-bath at $-15^{\circ} \mathrm{C}$. The column was programmed at $20^{\circ} \mathrm{C} \mathrm{min}-1$ between $50^{\circ} \mathrm{C}$ and $220^{\circ} \mathrm{C}$ with nitrogen as the carrier gas at a flow rate of $120 \mathrm{ml} \mathrm{min}^{-1}$ and the effluent trapped at the retention time corresponding to the elution of IBME. The trapped compound was taken up in NE250 scintillation fluid (15 ml, Nuclear Enterprises, Edinburgh, U.K.) and counted using an ICN Tracerlab Coru/matic 200 scintillation counter. 


\section{RESULTS AND DISCUSSION}

\section{Effect of composition of culture medium}

(I) Nature of carbon source. Initial experiments (Harper \& Gibbs, 1979) on the production of IBME by the Moraxella-like organism NCIB 11650 were conducted using nutrient agar slants in sealed vials. Increased quantities of IBME were formed when the organism was grown under aerobic conditions in shake flasks on a mineral salts medium with $\mathrm{NH}_{4} \mathrm{Cl}$ as sole nitrogen source and glucose or succinate as the sole carbon source. This finding seemed to preclude the possibility that IBME was a by-product of bacterial metabolism formed gratuitously on nutrient-rich media. Figures $1(a)$ and $(c)$ show the IBME concentration in the culture medium during growth of the Moraxella-like organism NCIB 11650 in the presence of $0.5 \%(\mathrm{w} / \mathrm{v})$ glucose and $0.5 \%$ (w/v) succinate, respectively, as sole carbon source. Also plotted is the total IBME generated per $\mathrm{ml}$ of culture medium during growth, i.e. IBME concentration in the medium adjusted for the rate of loss by diffusion out of solution.

IBME production and accumulation in the succinate-based medium began when the culture entered the exponential phase. Generation of IBME closely paralleled growth until the lateexponential phase when further production of the compound ceased. In the glucose-based medium IBME generation followed a similar course although it began at a somewhat later stage in the growth cycle. In both media the gradual decline in IBME concentration, which occurred in the stationary phase, followed the first-order kinetics found to be typical of diffusion from solution under these circumstances. This indicated that IBME did not accumulate merely as a transient intermediate in metabolism but was the end-product of a metabolic pathway which underwent no further transformation. However, the overall pattern of IBME generation, particularly in the succinate-based medium in which the rate of production of the compound directly reflected the rate of growth of the organism, was not typical of a secondary metabolite as the latter are usually synthesized as cultures enter the stationary phase (Weinberg, 1971). Thus, hydrogen cyanide production by Pseudomonas aeruginosa (Castric, 1975) or Chromobacterium violaceum (Rodgers \& Knowles, 1978) only began as the growth rate declined in the lateexponential and early-stationary phases.

Nevertheless, Demain et al. (1979) argued, on the basis of a number of investigations of antibiotic production, that secondary metabolites should not be defined simply as compounds produced after growth has ceased. They pointed out that antibiotic production was often growth associated in one medium but not in another, where the compounds were produced after growth (Pirt \& Righelato, 1967; Ito et al., 1969; Malik \& Vining, 1970). These authors concluded that the only valid definition of a secondary metabolite was that it is a molecule not required for growth of the organism that produces it.

Methacrylonitrile, isobutyronitrile and a compound tentatively identified as methacrylaldoxime $O$-methyl ether were also reported by Harper \& Gibbs (1979) as being formed by the Moraxella-like organism NCIB 11650 when cultured on nutrient agar slants in sealed vials at low oxygen concentrations. No trace of such compounds was observed on GC/MS of the headspace above cultures of this bacteria when grown in shake flasks on liquid media even under conditions of restricted oxygen supply with nutrient broth as the culture medium. It therefore seemed likely that production of these compounds was unique to cultures of the bacteria grown on slants under the conditions described.

(2) Supplementation with valine. Harper \& Gibbs (1979) established that on nutrient agar slants production of IBME by the Moraxella-like organism NCIB 11651 could be enhanced by enrichment of the medium with L-valine and suggested that valine was the probable precursor of IBME. The relationship between the concentration of L-valine employed to supplement a glucose-based medium and the peak concentration of IBME attained in the culture medium during growth of strain NCIB 11650 was investigated in more detail. Stimulation of IBME production was observed at all levels of supplementation examined up to $0.6 \%(\mathrm{w} / \mathrm{v})$, with maximum enhancement being attained with $0 \cdot 2 \%(\mathrm{w} / \mathrm{v})$ and $0 \cdot 3 \%(\mathrm{w} / \mathrm{v}) \mathrm{L}$-valine. Thus, whilst cultures on unsupplemented medium showed a peak IBME concentration of $4.2 \mu \mathrm{g} \mathrm{ml}^{-1}$, cultures grown in the presence of $0 \cdot 2 \%(w / v)$ L-valine gave a peak concentration of IBME of 


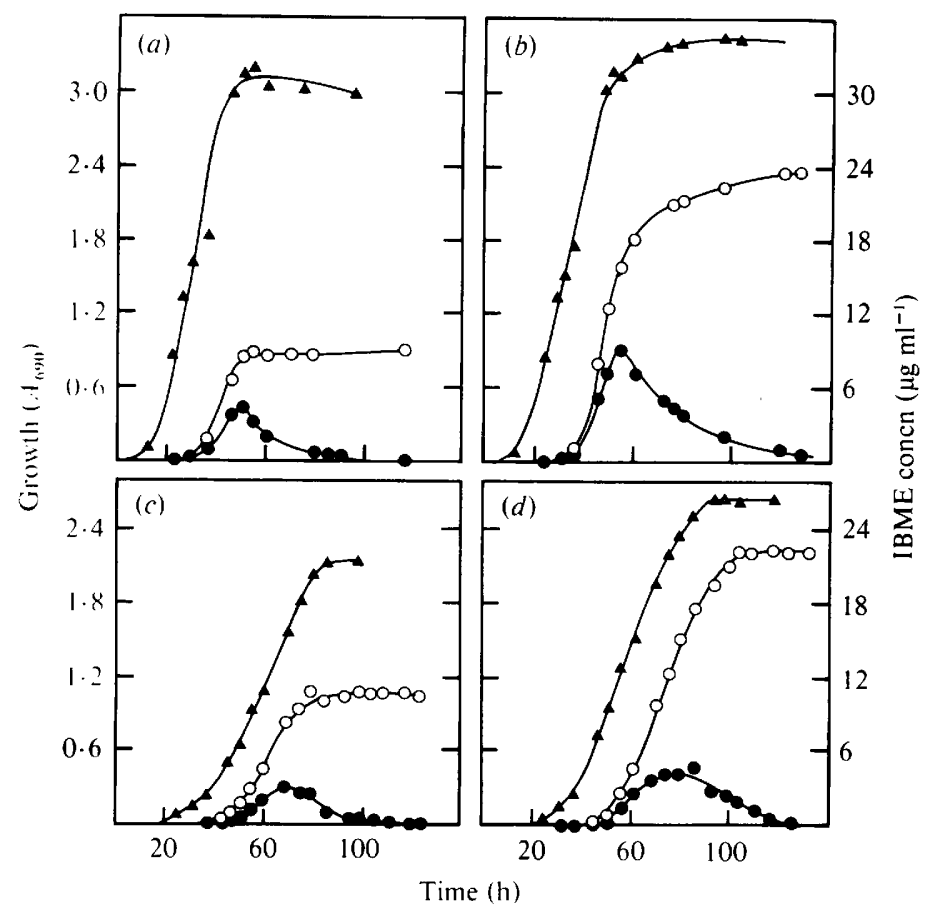

Fig. 1. Growth of Moraxella-like organism NCIB 11650 on glucose and succinate with and without added valine showing concentration of IBME and total production of IBME. The organism was grown at $15{ }^{\circ} \mathrm{C}$ on normal medium containing $(a) 0.5 \%(\mathrm{w} / \mathrm{v})$ glucose; $(b) 0.5 \%(\mathrm{w} / \mathrm{v})$ glucose $+0.2 \%(\mathrm{w} / \mathrm{v})$ valine; $(c) 0.5 \%(\mathrm{w} / \mathrm{v})$ succinate; $(d) 0.5 \%(\mathrm{w} / \mathrm{v})$ succinate $+0.2 \%(\mathrm{w} / \mathrm{v})$ valine. Growth and IBME concentrations were assayed as described in Methods. $\mathbf{A}$, Growth;, IBME concentration in culture medium; $O$, total production of IBME per ml culture medium.

$11.6 \mu \mathrm{g} \mathrm{ml}^{-1}$. Although enrichment of culture medium with $0.2 \%(\mathrm{w} / \mathrm{v})$ DL-valine gave a peak IBME concentration of a similar magnitude to that observed with L-valine, supplementation with the D-isomer $(0.2 \%$, w/v) did not appear to affect formation of the compound to any significant extent, indicating that if indeed valine acts as a precursor of IBME, the metabolic pathway is stereospecific to the L-isomer and the metabolism of the latter is not competitively inhibited by the presence of the D-isomer.

The effects of L-valine supplementation at $0.2 \%(w / v)$ on growth, concentration and total production of IBME on glucose-and succinate-based media, respectively, are shown in Figs $1(b)$ and $(d)$. It is immediately apparent by comparison with Figs $1(a)$ and $(c)$ that the presence of valine, whilst having comparatively little effect on growth, caused an approximately two- to threefold stimulation not only of peak IBME concentration attained in the medium, but also of total IBME production. However, supplementation of this nature did not appear to alter the phase of the growth cycle in which IBME production occurred.

(3) Concentration of carbon and nitrogen sources. The effects of glucose concentration in the culture medium on total IBME production and growth by the Moraxella-like organism NCIB 11650 in the presence and absence of $0.2 \%(\mathrm{w} / \mathrm{v}) \mathrm{L}$-valine are shown in Fig. 2. The organism showed no growth on valine as sole carbon source. Increasing glucose concentration was accompanied by increased total production of IBME up to a glucose concentration of $0.5 \%$ $(w / v)$. At glucose levels above this figure IBME yield declined despite the fact that cell growth yield continued to increase. The suppression of secondary metabolite production by higher concentrations of glucose and other readily utilizable carbon sources has been noted by Drew \& Demain (1977) and Demain et al. (1979). The ratio between IBME production by valinesupplemented cultures and those without the addition of the amino acid remained in the region of $2 \cdot 5: 1$ regardless of glucose concentration. 


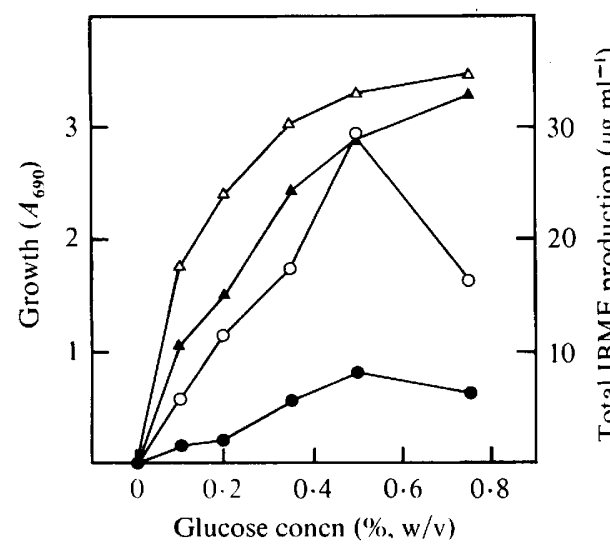

Fig. 2

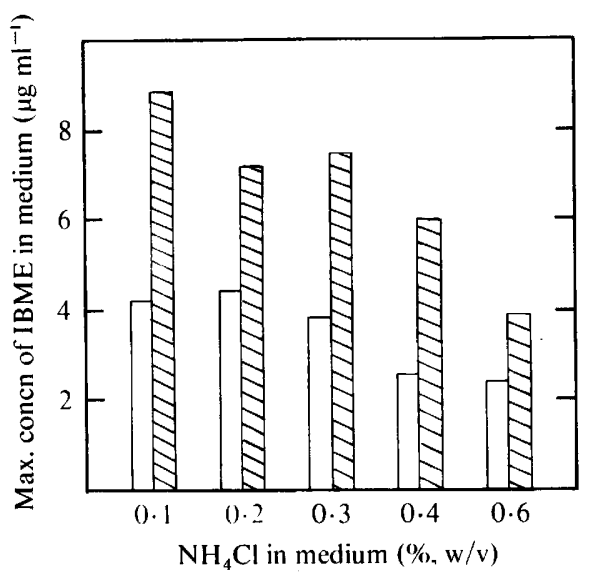

Fig. 3

Fig. 2. Effect of glucose concentration on total IBME production and growth yield of Moraxella-like organism NCIB 11650 . The organism was grown at $15^{\circ} \mathrm{C}$ on medium containing different concentrations of glucose with and without the addition of valine. Growth yield in the presence $(\triangle)$ and absence $(\Lambda)$ of $0.2 \%(w / v)$ valine and total IBME production per $\mathrm{ml}$ culture medium in the presence $(O)$ and absence $(O)$ of $0.2 \%(w / v)$ valine were measured.

Fig. 3. Effect of $\mathrm{NH}_{4} \mathrm{Cl}$ concentration on maximum IBME concentration attained during growth of Moraxella-like organism NCIB 11650 on $0.5 \%(w / v)$ glucose. The organism was grown at $15{ }^{\circ} \mathrm{C}$ on medium containing $0.5 \%(\mathrm{w} / \mathrm{v})$ glucose and different concentrations of $\mathrm{NH}_{4} \mathrm{Cl}$ in the presence and absence of $0.2 \%(\mathrm{w} / \mathrm{v})$ valine. IBME concentrations during growth were measured in the usual manner. Maximum IBME concentrations attained in the presence (hatched columns) and absence of $0.2 \%(w / v)$ valine are recorded.

The effect on IBME concentrations of altering the concentration of $\mathrm{NH}_{4} \mathrm{Cl}$ as nitrogen source in the presence of $0.5 \%(\mathrm{w} / \mathrm{v})$ glucose as carbon source is shown in Fig. 3. Levels of $\mathrm{NH}_{4} \mathrm{Cl}$ in excess of $0 \cdot 2 \%(\mathrm{w} / \mathrm{v})$ were associated with reduced formation of IBME, although total cell growth remained unchanged. Both cultures supplemented with valine and those without such addition showed similar behaviour in this respect. Nitrogen catabolite repression of secondary metabolism by readily used nitrogen sources such as ammonia has been observed in a number of studies (Drew \& Demain, 1977). Only poor growth was observed when the organism was grown on $0.5 \%$ (w/v) glucose with $0.2 \%$ (w/v) valine as sole nitrogen source and IBME concentration in the medium did not rise above $0.4 \mu \mathrm{g} \mathrm{ml}^{-1}$.

(4) Supplementation with amino acids other than valine. The Moraxella-like organism $\mathrm{NCIB} 11650$ was grown on media containing $0.5 \%(\mathrm{w} / \mathrm{v})$ glucose and $0.1 \%(\mathrm{w} / \mathrm{v}) \mathrm{NH}_{4} \mathrm{Cl}$ which were supplemented with various amino acids $(0.2 \%, \mathrm{w} / \mathrm{v})$, either alone or in combination with $\mathrm{L}-$ valine $(0 \cdot 2 \%, w / v)$. IBME formation was relatively unaffected by supplementation of the culture medium with L-leucine or L-isoleucine and analysis of the headspace above samples of the culture medium by GC/MS revealed no evidence of homologues of IBME derived from these amino acids, e.g. isovaleraldoxime $O$-methyl ether from leucine. This observation confirmed that the enzymes of the metabolic route to IBME were specific to the $L$-isomer of valine and metabolites derived from it. Production of IBME in the presence of valine was not markedly affected by either leucine or isoleucine.

Glycine and methionine, both of which strongly promoted cyanogenesis in Chromobacterium violaceum (Rodgers \& Knowles, 1978), failed to stimulate IBME production and indeed methionine quite strongly inhibited the process, a maximum concentration of only $2 \cdot 2 \mu \mathrm{g} \mathrm{IBME} \mathrm{ml} \mathrm{I}^{-1}$ being attained in the absence of valine and $8.5 \mu \mathrm{g} \mathrm{IBME} \mathrm{ml}^{-1}$ when valine was present. Supplementation of the medium with alanine caused an approximately twofold increase to $7.6 \mu \mathrm{g} \mathrm{ml}^{-1}$ in the maximum IBME concentration observed. This stimulation was tentatively ascribed to the fact that valine and alanine are both derived from pyruvate and thus the presence of alanine in the medium could have resulted in an increased throughput of pyruvate to valine. 
In the presence of exogenous valine, alanine had little or no stimulatory effect on IBME production, which would tend to support this hypothesis.

$\mathrm{L}-O$-Methylthreonine, a structural analogue of valine, has been reported by Tapper $\&$ Butler (1972) to strongly inhibit linamarin biosynthesis from valine via isobutyraldoxime in flax. In the present study L-O-methylthreonine showed no effect on bacterial IBME production either in the presence or absence of added valine, demonstrating yet again the high degree of specificity of the enzymic conversion of valine to IBME.

(5) Phosphate and $\mathrm{Fe}^{3+}$ concentrations. The production of secondary metabolites, notably antibiotics and the ergot alkaloids, is frequently inhibited by concentrations of inorganic phosphate in the culture medium which are not inhibitory to growth (Weinberg, 1971, 1974; Drew \& Demain, 1977). Similarly, cyanogenesis by Pseudomonas aeruginosa was inhibited by phosphate concentrations greater than $10 \mathrm{~mm}$ (Castric, 1975). In the present study with the Moraxella-like organism NCIB 11650 grown on medium containing $0.5 \%(\mathrm{w} / \mathrm{v})$ glucose and $0.2 \%(\mathrm{w} / \mathrm{v})$ valine, increasing the phosphate concentration from the normal level of $80 \mathrm{~mm}$ markedly suppressed IBME production. Thus, whilst $80 \mathrm{~mm}$-phosphate resulted in a maximum concentration of $10.2 \mu \mathrm{g} \mathrm{ml}^{-1}$ being attained in the medium during growth, $160 \mathrm{mM}$-phosphate gave only $4.4 \mu \mathrm{g}$ IBME $\mathrm{ml}^{-1}$ and $320 \mathrm{mM}$-phosphate almost completely inhibited IBME production, with a maximum IBME concentration of only $0.6 \mu \mathrm{g} \mathrm{ml}^{-1}$ being attained in the medium during growth.

The concentration of metal ions such as $\mathrm{Fe}^{3+}$ can also affect the formation of secondary metabolites (Weinberg, 1970). Thus cyanogenesis by Pseudomonas aeruginosa exhibited an exponential response to increased $\mathrm{Fe}^{3+}$ concentration in the medium up to $0.3 \mathrm{~mm}-\mathrm{Fe}^{3+}(\mathrm{Cas}-$ tric, 1975). However, IBME production by the Moraxella-like organism NCIB 11650 was not promoted by $\mathrm{Fe}^{3+}$ concentrations in excess of the normal media concentration of $1.2 \mu \mathrm{M}$. Indeed, increasing $\mathrm{Fe}^{3+}$ concentration to $26 \mu \mathrm{M}$ resulted in a depression of the maximum IBME concentration attained in medium containing $0.5 \%(\mathrm{w} / \mathrm{v})$ glucose and $0.2 \%(\mathrm{w} / \mathrm{v})$ valine from 10.2 to $6.4 \mu \mathrm{g} \mathrm{ml}^{-1}$. Further increase in $\mathrm{Fe}^{3+}$ concentration to $250 \mu \mathrm{M}$ resulted in no further reduction in IBME yield.

\section{Effect of temperature}

Both the maximum concentration of IBME in the medium and the total production of IBME by the Moraxella-like organism NCIB 11650 grown at different temperatures on succinatebased medium in the presence of valine is shown in Fig. 4. Also given is the maximum growth rate at each temperature expressed as the population doubling time. The optimum temperature for production of IBME was $15^{\circ} \mathrm{C}$. Although the concentrations of IBME reached in the media were higher at temperatures below $15^{\circ} \mathrm{C}$, when correction was made for the lower rate of diffusion of IBME from solution at such temperatures, it was apparent that the yield of IBME slowly declined below $15^{\circ} \mathrm{C}$. Above this temperature total production of IBME also sharply decreased and at the optimum temperature for cell growth $\left(17.5^{\circ} \mathrm{C}\right)$ it was only about half of that at $15^{\circ} \mathrm{C}$. At temperatures above the optimum for cell growth, formation of IBME appeared to be influenced to a far greater extent by increase in temperature than was cell growth. Thus at $21.5^{\circ} \mathrm{C}$ IBME production was almost completely repressed whilst growth rate was only slightly reduced. These findings are consistent with the general observation that the biosynthesis of secondary metabolites is normally confined to a narrower range of temperature than cell division (Weinberg, 1971).

\section{Incorporation of $\left[{ }^{14} \mathrm{C}\right]$ valine into $\mathrm{IBME}$}

To confirm unequivocally that the stimulatory effect of L-valine on IBME generation was attributable to its role as a metabolic precursor of the compound, the Moraxella-like organism NCIB 11650 was grown on $0.5 \%(w / v)$ glucose-containing medium in the presence of $\left[{ }^{14} \mathrm{C}\right] \mathrm{va}-$ line, and the degree of labelling of the IBME formed was measured. The results of two series of experiments comparing the incorporation of $L-\left[U-{ }^{14} \mathrm{C}\right]$ valine and $L-\left[1-{ }^{14} \mathrm{C}\right]$ valine into IBME are shown in Table 1. Growth in the presence of uniformly labelled valine led to the formation of IBME with a specific activity equivalent to about $70 \%$ of that predicted if all the compound 


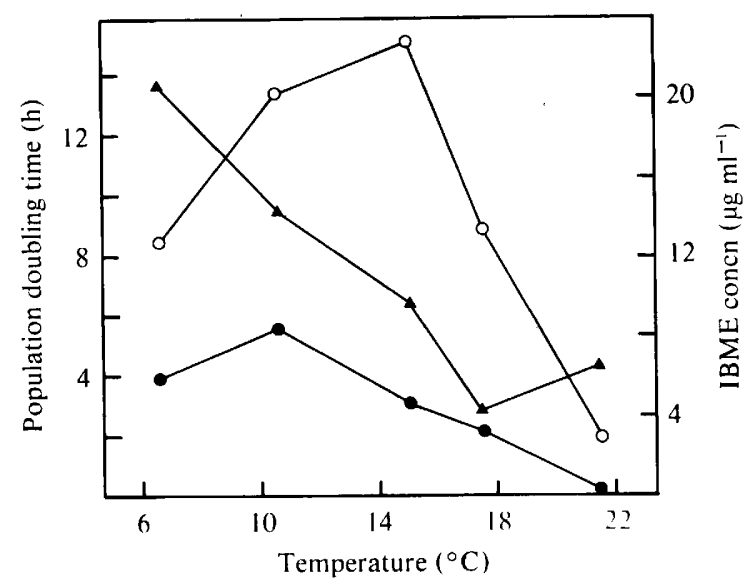

Fig. 4. Effect of temperature on growth rate and IBME production by Moraxella-like organism NCIB 11650 grown on succinate medium in the presence of valine. The organism was grown at different temperatures on $0.5 \%(\mathrm{w} / \mathrm{v})$ succinate medium containing $0.2 \%(\mathrm{w} / \mathrm{v})$ valine; growth and IBME concentrations were monitored in the usual manner. $\Delta$, Maximum growth rate expressed as population doubling time;, maximum IBME concentration attained in medium; $O$, total production of IBME per $\mathrm{ml}$ of medium.

Table 1. Incorporation of $\left[{ }^{14} \mathrm{C}\right]$ valine into IBME

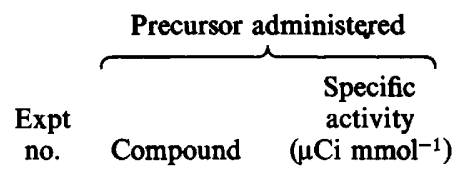

\begin{tabular}{|c|c|c|c|}
\hline \multicolumn{4}{|c|}{ IBME produced } \\
\hline $\begin{array}{c}\text { Specific } \\
\text { activity* } \\
\left(\mu \mathrm{Ci} \mathrm{mmol}{ }^{-1}\right)\end{array}$ & $\begin{array}{c}\text { Predicted } \\
\text { specific activity† } \\
\left(\mu \mathrm{Ci} \mathrm{mmol}^{-1}\right)\end{array}$ & $\begin{array}{c}\text { Percentage } \\
\text { incorporation of } \\
\text { radioactivity* }\end{array}$ & $\begin{array}{l}\text { Predicted percentage } \\
\text { incorporation of } \\
\text { radioactivity } \dagger\end{array}$ \\
\hline $\begin{array}{l}3.52 \pm 0.03 \\
0.14 \pm 0.01 \\
5.30 \pm 0.04 \\
0.03 \pm 0.01\end{array}$ & $\begin{array}{l}5 \cdot 2 \\
0 \\
6 \cdot 8 \\
0\end{array}$ & $\begin{array}{r}67.7 \pm 0.6 \\
2.5 \pm 0.2 \\
77.9 \pm 0.6 \\
0.6 \pm 0.1\end{array}$ & $\begin{array}{r}100 \\
0 \\
100 \\
0\end{array}$ \\
\hline
\end{tabular}
1 L-[U- $\left.{ }^{14} \mathrm{C}\right]$ Valine $\quad 5 \cdot 6$ $\mathrm{L}-\left[1{ }^{-14} \mathrm{C}\right]$ Valine $\quad 5.9$
2 L-[U-14 C]Valine $\quad \mathbf{7 \cdot 3}$ $L-[1-14 \mathrm{C}]$ Valine $\quad 5.9$ $0.03 \pm 0.01$

* Mean values \pm standard error

$\dagger$ Assuming (i) IBME derived from valine with loss of carboxyl carbon, (ii) no endogenously formed valine is incorporated into IBME, (iii) the methoxyl group of IBME is not labelled.

apart from the methoxyl group was derived from exogenous valine. Since, even when valine was supplied in the culture medium a substantial quantity of IBME could be synthesized from endogenously formed (and hence unlabelled) valine, this degree of incorporation was quite consistent with the hypothesis that all the IBME was derived from valine. As biosynthesis of IBME from this amino acid necessitated loss of the carboxyl group, the IBME produced by the organism in the presence of $\mathrm{L}-\left[1-{ }^{14} \mathrm{C}\right]$ valine should show an insignificant degree of labelling. The results in Table 1 demonstrate that this is indeed the case, the specific activity of IBME formed being less than $3 \%$ of that of the valine supplied.

\section{Comparison of IBME production by different bacterial species}

In an investigation of spoilage odours arising from the growth in pure culture of 20 organisms on beef (Gibbs et al., 1979), IBME was identified as a volatile headspace component generated not only by the Moraxella-like organism NCIB 11650 but also by two other species, Alcaligenes sp. and the Moraxella-like organism NCIB 11651. Moreover, Harper \& Gibbs (1979) noted that the mass spectrum of IBME was very similar to that of an unidentified volatile metabolite described by Freeman et al. (1976) as being formed on chicken meat by strains of Pseudomonas putida and a Moraxella sp. (now reclassified as Pseudomonas sp. NCIB 11653). To assess the relative rates and significance of IBME production by different species and to confirm that the unidentified volatile compound described by Freeman et al. (1976) was definitely IBME, growth 
Table 2. Comparison of IBME formation by different bacterial species

\begin{tabular}{|c|c|c|c|c|}
\hline & \multicolumn{2}{|c|}{$\begin{array}{c}\text { Glucose }(0.5 \%, w / v) \\
\text { medium }\end{array}$} & \multicolumn{2}{|c|}{$\begin{array}{l}\text { Glucose }(0.5 \%, \text { w/v }) \text { medium } \\
\text { supplemented with valine } \\
(0.2 \%, w / v)\end{array}$} \\
\hline rganism & $\begin{array}{l}\text { Max. IBME } \\
\text { concn attained } \\
\text { in medium } \\
\left(\mu \mathrm{g} \mathrm{ml}^{-1}\right)\end{array}$ & $\begin{array}{l}\text { Total IBME } \\
\text { production } \\
\text { in medium } \\
\left(\mu \mathrm{g} \mathrm{ml}^{-1}\right)\end{array}$ & $\begin{array}{l}\text { Max. IBME } \\
\text { concn attained } \\
\text { in medium } \\
\left(\mu \mathrm{g} \mathrm{ml}^{-1}\right)\end{array}$ & $\begin{array}{l}\text { Total IBME } \\
\text { production } \\
\text { in medium } \\
\left(\mu \mathrm{g} \mathrm{ml}^{-1}\right)\end{array}$ \\
\hline $\begin{array}{l}\text { ike organism } \\
50\end{array}$ & $4 \cdot 3$ & 8.8 & $9 \cdot 1$ & 23.8 \\
\hline $\begin{array}{l}\text { like organism } \\
651\end{array}$ & $2 \cdot 4$ & $5 \cdot 0$ & $11 \cdot 2$ & $44 \cdot 7$ \\
\hline p. & 9.0 & $19 \cdot 6$ & $30 \cdot 0$ & 89.7 \\
\hline $\begin{array}{l}s \text { sp. } \\
53\end{array}$ & $1 \cdot 3$ & $3 \cdot 1$ & $1.9^{*}$ & $5 \cdot 3^{*}$ \\
\hline
\end{tabular}
text).

- Values given are approximations since masss spectrometry indicated methyl isobutyrate also present (see

and IBME production by cultures of the Moraxella-like organisms NCIB 11650 and NCIB 11651, the Alcaligenes sp., and the Pseudomonas sp. NCIB 11653 isolated by Freeman et al. (1976) were compared under identical conditions using GC and GC/MS.

Both the maximum IBME concentration attained in the culture medium and the total IBME production per $\mathrm{ml}$ of medium are tabulated for each organism when grown at $15{ }^{\circ} \mathrm{C}$ on $0.5 \%$ (w/v) glucose medium with and without supplementation by $0.2 \%(w / v)$ valine (Table 2$)$. Large differences were clearly discernible between species as regards IBME production both in the presence and in the absence of valine. Alcaligenes sp. gave by far the greatest yield of the compound, generating almost $0.1 \mathrm{mg} \mathrm{ml}^{-1}$ on the valine-supplemented medium. On the other hand, the Pseudomonas sp. isolated by Freeman et al. (1976), although definitely confirmed by GC/MS as forming the compound, only produced comparatively small quantities. When the latter organism was cultured in the presence of valine, GC/MS of the headspace above the culture medium indicated that methyl isobutyrate was also present. Since this compound possessed a similar retention time to IBME under the GC conditions employed for quantitation of IBME, the values given in Table 2 for production of the latter compound in the presence of valine are approximations only. Lee et al. (1979) have also detected methyl isobutyrate as a headspace component when this organism was grown on Trypticase soy agar supplemented with yeast extract.

The Moraxella-like organism NCIB 11650 chosen for more detailed study was obviously intermediate with regard to its capacity for IBME production, generating relatively high levels in $0.5 \%(\mathrm{w} / \mathrm{v})$ glucose alone, but showing only a comparatively small increase in IBME production on supplementation of the medium with valine. It was noteworthy that the relationship between the kinetics of growth and IBME production by Alcaligenes sp. and the other Moraxella-like organism NCIB 11651 both in the presence and in the absence of exogenous valine, was rather different from that of NCIB 11650. Thus IBME formation was retarded until the end of the exponential phase and most biosynthesis occurred in the early-stationary phase, as can be seen from Figs 5(a) and (b), which show the behaviour of cultures of the two organisms in the presence of exogenous valine. This pattern was more typical of secondary metabolite formation than that observed with the Moraxella-like organism NCIB 11650. Secondary metabolites do not usually appear during active growth because the enzymes responsible for their biosynthesis are repressed during the exponential phase (Drew \& Demain, 1977; Weinberg, 1971).

\section{Confirmation of methacrylaldoxime $O$-methyl ether as a volatile catabolite of valine on slants}

Harper \& Gibbs (1979) reported the identification of, in addition to IBME, both isobutyronitrile and methacrylonitrile as components of headspace above cultures of both the Moraxella- 


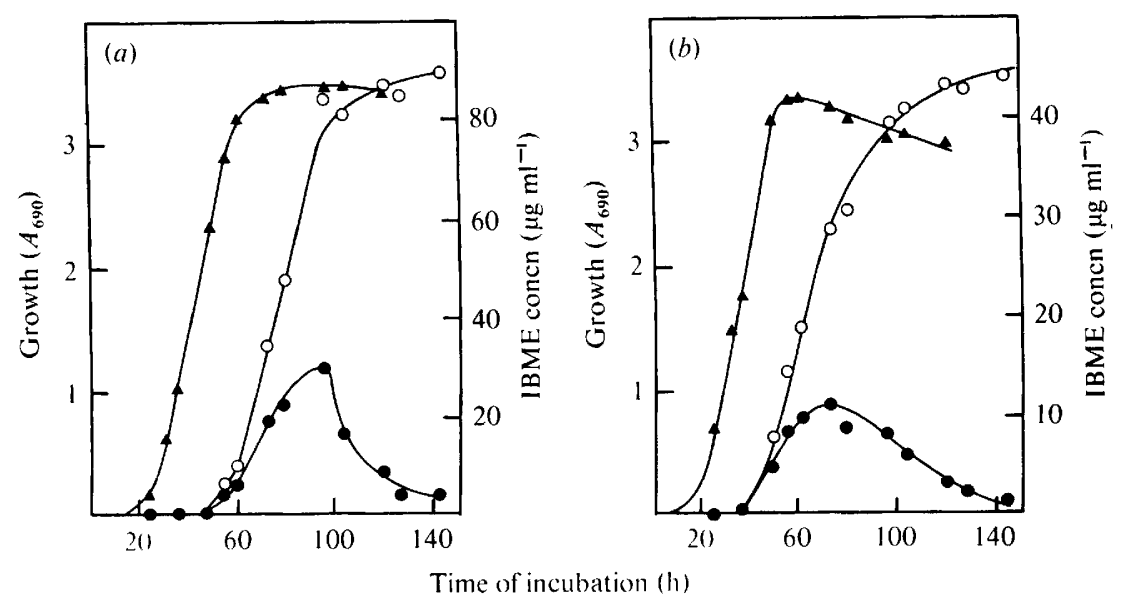

Fig. 5. Growth and IBME production by $(a)$ Alcaligenes sp. and (b) the Moraxella-like organism NCIB 11651. The organisms were grown at $15{ }^{\circ} \mathrm{C}$ on medium containing $0.5 \%(\mathrm{w} / \mathrm{v})$ glucose and $0 \cdot 2 \%$ $(w / v)$ valine; growth and IBME concentrations were assayed in the usual manner. $\boldsymbol{A}$, Growth; $\boldsymbol{O}$, IBME concentration in medium; $O$, total production of IBME per ml of medium.

like organisms NCIB 11650 and NCIB 11651 on nutrient agar slants. Another apparently structurally related catabolite was also present and was tentatively identified as methacrylaldoxime $O$-methyl ether on the basis of its mass spectrum, which showed a molecular ion at $\mathrm{m} / \mathrm{e} 99$ and major fragmentation peaks at $m / e 72,71,57,41,40$ and 39 . Difficulties in the chemical synthesis of this compound prevented an unequivocal identification. However, the compound has now been prepared by the action of methoxyamine hydrochloride on methacrolein as described in Methods. The mass spectrum and GC retention time of the synthetic compound were found to be identical to that of the unknown volatile confirming the tentative identification of Harper \& Gibbs (1979).

\section{Biochemical significance and biosynthesis of IBME}

The work presented in this paper indicates that IBME is a novel volatile secondary metabolite produced from valine by species of several genera of bacteria when cultured under a wide range of environmental conditions. When such bacteria are grown on nutrient agar slants in sealed vials, particularly at low oxygen concentrations, several related metabolites can be formed in addition to IBME. However, in batch culture under aerobic conditions on defined media, only IBME can be detected. Although oximes have been implicated in plants as intermediates in the biosynthesis of secondary metabolites such as cyanogenic glycosides (Conn, 1980), glucosinolates (Underhill, 1980) and also indoleacetonitrile (Mahadevan, 1973), their native pool size, like that of many intermediates, is so small that it has not been possible to isolate them chemically. Their formation in plants from the corresponding ${ }^{14} \mathrm{C}$-labelled amino acid in vivo has only been demonstrated by means of trapping experiments or specific inhibitors. The production of IBME by bacteria is, therefore, the first reported instance in which an oxime, albeit methylated, is per se the final product of a pathway of secondary metabolism and is consequently present in relatively large amounts. A survey of the literature has revealed no previous mention of methyl ethers of oximes occurring in nature either as intermediates in secondary metabolism or as secondary metabolites themselves. However, such compounds have a number of features which render them particularly well suited for the role of secondary metabolite if, as Weinberg (1970) has suggested, the function of secondary metabolism is to shunt potentially harmful levels of primary metabolites into innocuous products during the stationary phase. Thus IBME, which on this hypothesis acts as a metabolic sink for excess valine, is highly volatile, of relatively low solubility in water and possesses a non-ionizable lipophilic nature. Such properties enable it to diffuse freely through the cell membrane and from the surrounding aqueous phase into the 


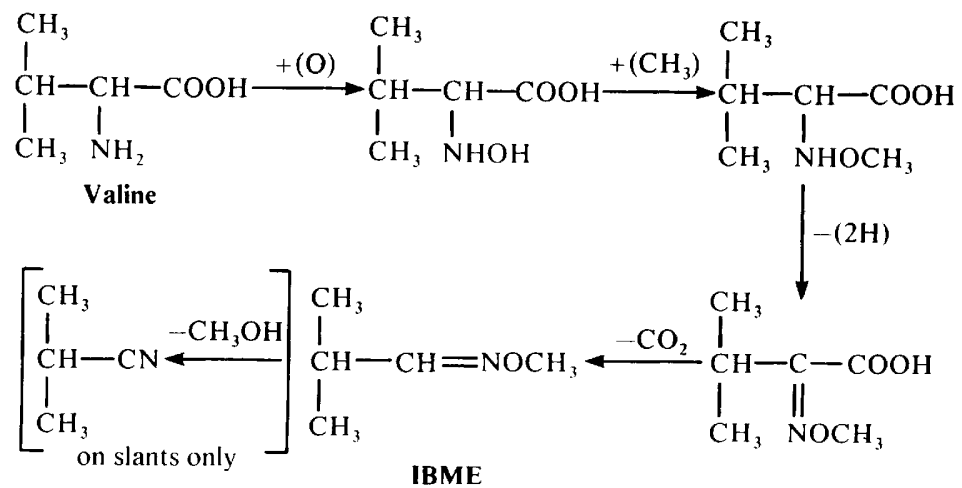

Fig. 6. Possible route for formation of IBME and isobutyronitrile from valine.

atmosphere where it should exert no further influence on cellular metabolism. The shunting of excess amino acid into a volatile compound in this manner is analogous to the conversion of glycine to hydrogen cyanide by Pseudomonas aeruginosa (Castric, 1975) and Chromobacterium violaceum (Rodgers \& Knowles, 1978).

A possible route for the biosynthesis of IBME from valine is shown in Fig. 6. The pathway must involve an initial $N$-hydroxylation step similar to that postulated by Tapper \& Butler (1971) for the first stage in the biosynthesis of linamarin from valine by flax and that demonstrated by Moeller \& Conn (1977) as the initial step in the formation of dhurrin from tyrosine in sorghum. $\mathrm{N}$-Hydroxylation has also been observed in the biosynthesis of the antibiotic, hadacidin, from glycine by Stevens \& Emery (1966). The sequence in which later reactions in the metabolic pathway occur is uncertain, but must involve a methylation step and an oxidation of the hydroxy or methoxy amino acid to the oximino or methoximino acid in a manner similar to that suggested by Kindl \& Underhill (1968) for the conversion of $N$-hydroxyphenylalanine to phenylacetaldoxime in the biosynthesis of glucosinolates in Tropaeolum majus. The final stage in the biosynthetic route to IBME is probably decarboxylation of the methoximino acid.

The further catabolism of IBME to isobutyronitrile which was observed on nutrient agar slants and during meat spoilage, would presumably involve a loss of methanol from the compound in a manner analogous to the dehydration of isobutyraldoxime to isobutyronitrile postulated by Tapper \& Butler (1971) in the biosynthesis of linamarin. The presence in addition of methacrylaldoxime $O$-methyl ether and methacrylonitrile in headspace above slants can be explained by a similar reaction occurring after dehydration of the 3-hydroxylated derivative of IBME.

We wish to thank Mrs S. Moore for her skilled technical assistance, Dr D. Stewart for kindly making the necessary biometric calculations using his computer modelling programme and Dr D. Johnston for helpful discussions.

\section{REFERENCES}

CASTRIC, P. A. (1975). Hydrogen cyanide, a secondary metabolite of Pseudomonas aeruginosa. Canadian Journal of Microbiology 21, 613-618.

ConN, E. E. (1980). Cyanogenic glycosides. In Secondary Plant Products, pp. 461-492. Edited by E. A. Bell \& B. V. Charlewood. Berlin, Heidelberg, New York: Springer-Verlag.

Demain, A. L., Kennel, Y. M. \& Aharonowitz, Y. (1979). Carbon catabolite regulation of secondary metabolism. Symposia of the Society for General Microbiology 29, 163-185.

DREW, S. W. \& DemaIN, A. L. (1977). Effect of primary metabolites on secondary metabolism. Annual Review of Microbiology 31, 343-356.
Freeman, L. R., Silverman, G. J., Angelini, P., MERritt, C., JR \& Esselen, W. B. (1976). Volatiles produced by microorganisms isolated from refrigerated chicken at spoilage. Applied and Environmental Microbiology 32, 222-231.

Gibbs, P. A., Patterson, J. T. \& HaRPer, D. B. (1979). Some characteristics of the spoilage of sterile beef by pure cultures of bacteria. Journal of the Science of Food and Agriculture 30, 1109-1110.

Hahlbrock, K., TAPPER, B. A., Butler, G. W. \& ConN, E. E. (1968). Conversion of nitriles and $\alpha$ hydroxynitriles to cyanogenic glucosides in flax seedlings and cherry laurel leaves. Archives of Biochemistry and Biophysics 125, 1013-1016. 
HARPER, D. B. (1980). The biogenesis of unusual volatile microbial metabolites of valine. Abstracts of 13 th FEBS Meeting, p. 273. Jerusalem.

HARPER, D. B. \& GiBBS, P. A. (1979). Identification of isobutyronitrile and isobutyraldoxime $O$-methyl ether as volatile microbial catabolites of valine. Biochemical Journal 182, 609-611.

ITO, M., AIDA, K. \& VemuRA, T. (1969). Studies on the bacterial formation of peptide antibiotic, colistin. 2 . On the biosynthesis of 6-methyloctanoic and isoctanoic acids. Agricultural and Biological Chemistry 33, 262-269.

KINDL, H. \& UNDERHIIL, E. W. (1968). Biosynthesis of mustard oil glucosides: $N$-hydroxyphenylalanine, a precursor of glucotropaeolin and a substrate for the enzymatic and nonenzymatic formation of phenylacetaldehyde oxime. Phytochemistry 7, 745-756.

LeE, M. L., Smith, D. L. \& Freeman, L. R. (1979). High-resolution gas chromatographic profiles of volatile organic compounds produced by microorganisms at refrigerated temperatures. Applied and Environmental Microbiology 37, 85-90.

Mahadevan, S. (1973). Role of oximes in nitrogen metabolism in plants. Annual Review of Plant Physiology 24, 69-88.

MaLIK, V. S. \& VINING, L. C. (1970). Metabolism of chloramphenicol by the producing organism. Canadian Journal of Microbiology 16, 173-179.

MoELlER, B. L. \& CONN, E. E. (1977). Biological formation of $N$-hydroxyamino acids. Proceedings of the Western Pharmacological Society 20, 103-107.

Patterson, J. T. \& Gibes, P. A. (1977). Incidence and spoilage potential of isolates from vacuum-packaged meat of high pH values. Journal of Applied Bacteriology 43, 25-38.
PIRT, S. J. \& RigheLATo, R. C. (1967). Effect of growth rate on the synthesis of penicillin by Penicillium chrysogenum in batch and chemostat cultures. $A p$ plied Microbiology 15, 1284-1290.

RODGers, P. B. \& KNowles, C. J. (1978). Cyanide production and degradation during growth of Chromobacterium violaceum. Journal of General Microbiology 108, 261-267.

STEVENS, R. L. \& EMERY, T. F. (1966). The biosynthesis of hadacidin. Biochemistry 5, 74-81.

TAPPER, B. A. \& BUTLER, G. W. (1971). Oximes, nitriles and 2-hydroxynitriles as precursors in the biosynthesis of cyanogenic glucosides. Biochemical Journal 124, 935-941.

TAPPER, B. A. \& BUTLER, G. W. (1972). Intermediates in the biosynthesis of linamarin. Phytochemistry 11, 1041-1046.

TAPPER, B. A., CONN, E. E. \& BUTLER, G. W. (1967). Conversion of $\alpha$-ketoisovaleric acid oxime and isobutyraldoxime to linamarin in flax seedlings. $A r-$ chives of Biochemistry and Biophysics 119, 593-595.

UNDERHILL, E. W. (1980). Glucosinolates. In Secondary Plant Products, pp. 493-511. Edited by E. A. Bell \& B. V. Charlewood. Berlin, Heidelberg, New York: Springer-Verlag.

WeINBERG, E. D. (1970). Biosynthesis of secondary metabolites : roles of trace metals. Advances in Microbial Physiology 4, 1-44.

WEINBERG, E. D. (1971). Secondary metabolism: raison d'être. Perspectives in Biology and Medicine 14, 565-577.

WEINBERG, E. D. (1974). Secondary metabolism: control by temperature and inorganic phosphate. Developments in Industrial Microbiology 15, 70-81. 